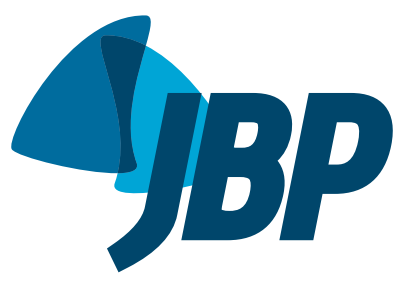

\title{
Should active case finding be conducted among patients with respiratory symptoms independently of local epidemiological settings?
}

\author{
Betina Mendez Alcântara Gabardo 0,2,a , Eliane Mara Cesário Pereira Maluf ${ }^{1,2, b}$, \\ Marianna Borba Ferreira de Freitas ${ }^{3, c}$, Bruno Alcântara Gabardo ${ }^{4, d}$
}

\section{TO THE EDITOR:}

Since the implementation of the directly observed treatment short course (DOTS) strategy by the World Health Organization, it has been recommended that patients presenting with respiratory symptoms (i.e., patients who have had cough and expectoration for three weeks or more) undergo microscopic examination of two sputum smears for early diagnosis of tuberculosis.

According to the Programa Nacional de Controle da Tuberculose (PNCT, Brazilian National Tuberculosis Control Program), the estimated prevalence of individuals with respiratory symptoms is $1 \%$ in the general population and $5 \%$ among those $\geq 15$ years of age seeking treatment at health care facilities (HCFs), the prevalence of active pulmonary tuberculosis among individuals with respiratory symptoms being $4 \%$. According to the World Health Organization, it is estimated that prevalence of respiratory symptoms is $5 \%$ at HCFs in developing countries. ${ }^{(1)}$ These rates are related to different epidemiological settings and can therefore vary depending on HCF and local population characteristics.

Many studies have focused on estimating the prevalence of individuals with respiratory symptoms either in the community or among those seeking treatment at HCFs. In the cities of Vitória(2) and Rio de Janeiro, (3) Brazil, the prevalence of individuals with respiratory symptoms among those seeking treatment at HCFs was $4.0 \%$ and $10.7 \%$, respectively. In the Federal District of Brasília, (4) Brazil, the prevalence of individuals with respiratory symptoms in the community ranged from $4.8 \%$ to $5.7 \%$. Few studies have simultaneously examined the prevalence of individuals with respiratory symptoms in the community and among those seeking treatment at HCFs.

The objective of the present study was to determine the prevalence of individuals with respiratory symptoms and of tuberculosis in the city of Paranaguá, Brazil, where the incidence of tuberculosis is high (i.e., 99/100,000 population). This was a descriptive study involving a population-based survey and a survey of patients seeking treatment at HCFs between September and November of 2010 , when the incidence of tuberculosis was $23 / 100,000$ population in the state of Paraná, Brazil and 37/100,000 population in the country as a whole.

Cluster sampling is recommended for population-based studies $^{(5)}$ and was used in the present study in order to obtain a representative sample of the community and of patients treated at HCFs, being weighted by population size and number of visits in the previous year so that neighborhoods that are more populous and HCFs that treat more patients had more clusters. Residents of special census tracts/"subnormal agglomerations" (i.e., slums) ${ }^{(6)}$ were excluded from the population-based (household) survey because the prevalence of respiratory symptoms and tuberculosis in such individuals is known to be high. Individuals seeking treatment at primary care clinics or in the Family Health Program participated in the survey of HCFs, regardless of the reason for seeking treatment. All participants were $\geq 10$ years of age and completed a questionnaire on sociodemographic data, duration of cough, and tuberculosis signs and symptoms.

Sample size was calculated by multiplying a simple random sampling formula $-\mathrm{n}=\mathrm{Nz}^{2} \mathrm{p}(1-\mathrm{p}) /\left[\mathrm{d}^{2}(\mathrm{~N}-1)+\right.$ $\left.z^{2} p(1-p)\right]-$ by the design effect $(D E=2)$ to correct for differences in sample size (within-cluster correlation). ${ }^{(2,5)}$

The community sample consisted of 1,020 individuals randomly selected from 30 clusters in the 17 most populous neighborhoods, with approximately 30 individuals in each cluster ( $p=$ prevalence of individuals with respiratory symptoms $=1 \%$ ). An estimated sample of $757 \mathrm{HCF}$ patients were selected from 25 clusters in nine active HCFs ( $p=5 \%$ of the total number of visits). For both samples, $z^{2}=1.96$ and $d=2 \%$.

Individuals presenting with productive cough were classified as having cough independently of the duration of cough; those with a $\geq 21$ day-history of cough were considered to have respiratory symptoms. Patients with bacteriologically confirmed pulmonary tuberculosis were defined as those with positive bacteriological findings, whereas patients with pulmonary tuberculosis not confirmed bacteriologically were defined as those diagnosed with tuberculosis on the basis of clinical and radiological criteria.

1. Complexo Hospital de Clínicas, Universidade Federal do Paraná - UFPR - Curitiba (PR) Brasil.

2. Programa de Pós-Graduação em Medicina Interna, Universidade Federal do Paraná - UFPR - Curitiba (PR) Brasil.

3. Programa de Controle de Tuberculose de Paranaguá, Paranaguá (PR) Brasil.

4. Centro de Pesquisa em Terapia Intensiva - CEPETI - Curitiba (PR) Brasil.

Financial support: This study received financial support from the Brazilian National Ministry of Health Projeto de Fortalecimento das Ações do Programa Nacional de Controle da Tuberculose (ENSP-011-LIV-10), in partnership with the Centro de Referência Professor Hélio Fraga da Escola Nacional de Saúde Pública Sergio Arouca da Fundação Oswaldo Cruz (CRPHF/ENSP/FIOCRUZ) and the Fundação Araucária (Programa de Pesquisa para o Sistema Único de Saúde 187/2010). a. (iD) https://orcid.org/0000-0003-2669-2079; b. (iD https://orcid.org/0000-0002-3060-7351; c. (iD) https://orcid.org/0000-0001-8766-9476;

d. (iD) https://orcid.org/0000-0002-4971-283X 


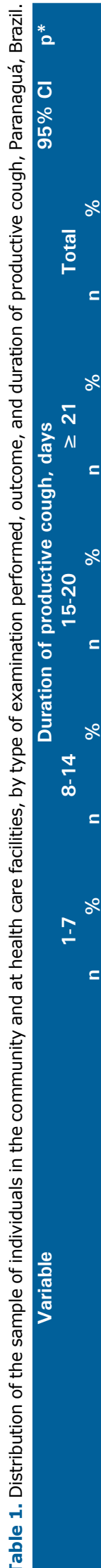

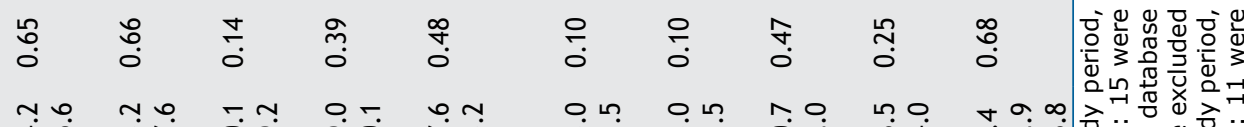

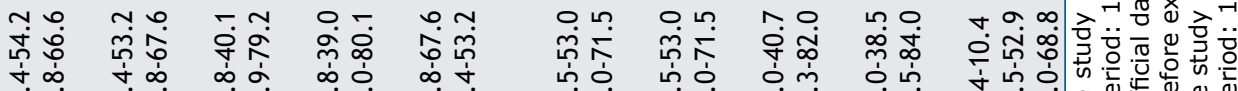

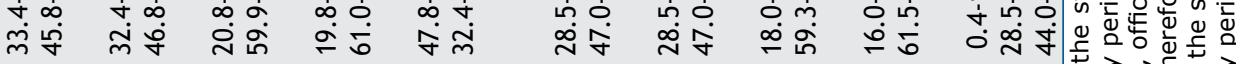
ㅇํ. นกน भुष भुष

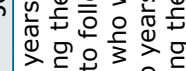

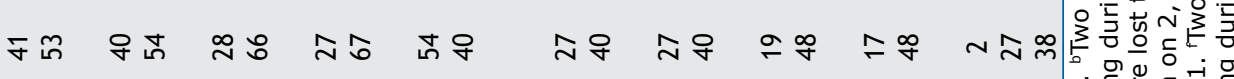

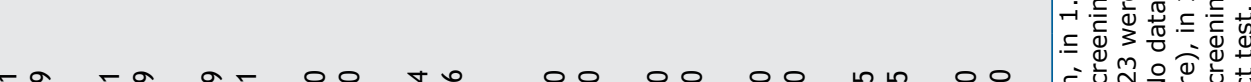

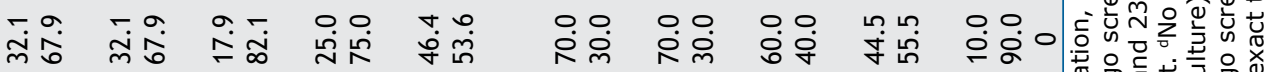

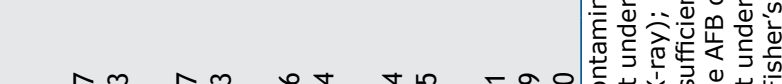

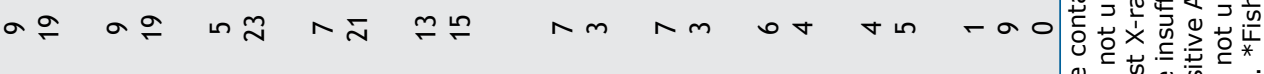

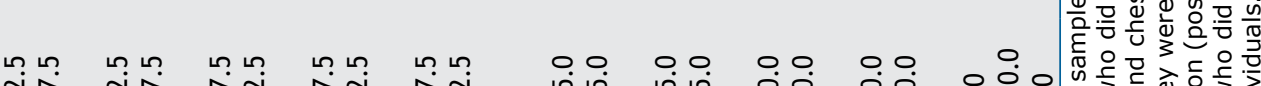

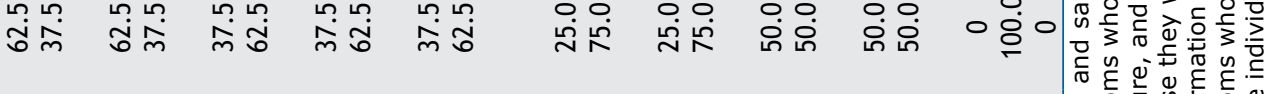

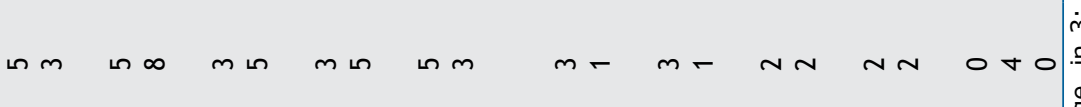

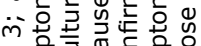

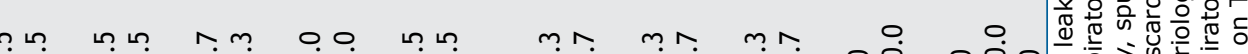

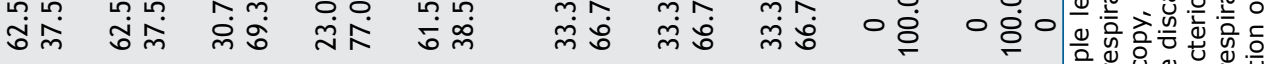

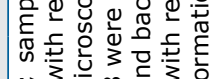

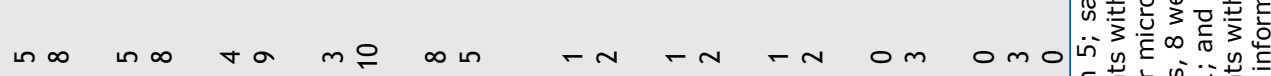

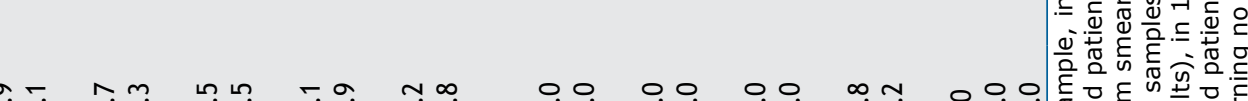

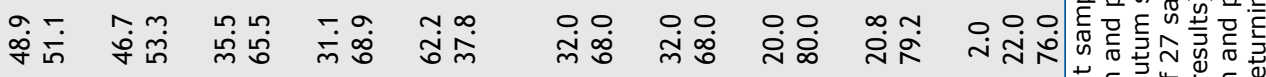
ก๊

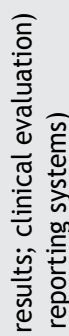

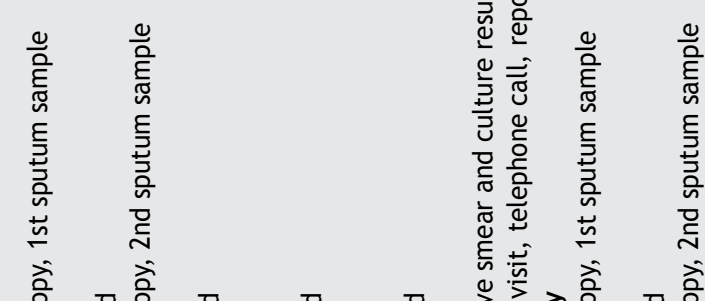

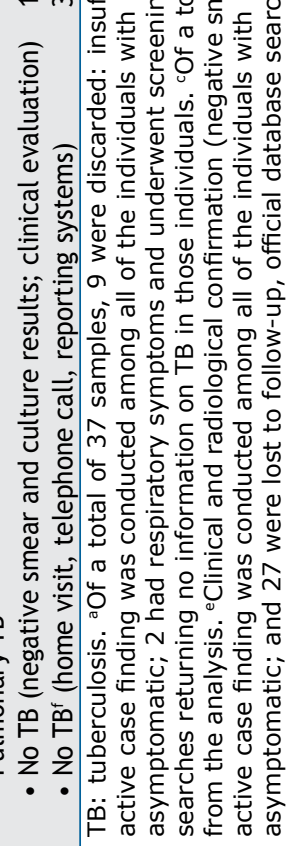


All of the individuals who presented with cough were instructed to undergo microscopic examination of two sputum smears and AFB culture. Individuals were given a sputum container for collection of spot sputum samples at HCFs and at home. All questionnaire data were double entered into an Epi data database, the program being used in order to validate variables of interest. Two years after the study period, active case finding (i.e., systematic screening for active tuberculosis) was conducted among all of the individuals with cough and patients with respiratory symptoms who did not undergo screening during the study period (Table 1 ). The chi-square test was used in order to compare the differences between proportions and to verify if they were significant; at frequencies lower than 5, the Fisher's exact test was used. The significance level adopted was $5 \%$, and statistical tests were performed using the statistical package Stata, version 13.0 (StataCorp LP, College Station, TX, USA).

The proportions of screened individuals were low in the community and at HCFs (Table 1). Most of the participants declined to provide a spot sputum sample and failed to return a sample.

Of a total of 94 individuals with cough in the community, 28 were considered to be individuals with respiratory symptoms (prevalence, $2.7 \% ; 95 \% \mathrm{CI}$ : 1.8-3.9\%). Of a total of 67 individuals presenting with cough to HCFs, 10 were considered to be individuals with respiratory symptoms (prevalence, $1.3 \% ; 95 \% \mathrm{CI}$ : $0.6-2.4 \%$ ). Tuberculosis was identified in 1 individual with a 5-day history of cough and in 1 individual with respiratory symptoms, the prevalence of tuberculosis among all of the individuals who presented with cough to HCFs therefore being $3 \%$.

The present population-based study sought to fill a gap in the literature by simultaneously examining the prevalence of individuals with respiratory symptoms and of tuberculosis in the community and among those seeking treatment at HCFs. Residents of special census tracts/subnormal agglomerations ${ }^{(6)}$ were excluded in an attempt to minimize selection bias. However, their exclusion and the low proportions of individuals undergoing sputum examination are limitations of the present study because they might have resulted in an underestimation of tuberculosis prevalence.

In the present study, the prevalence of individuals with respiratory symptoms in the community was higher than that detected under the PNCT. Our results are similar to those obtained in India $(2.7 \%)$, (7) Peru $(3.3-3.8 \%),{ }^{(8)}$ and in some regions of the Federal District of Brasília $(4.8-5.7 \%){ }^{(4)}$ all of which are highly endemic for tuberculosis.

Our population-based survey revealed no cases of tuberculosis, a finding that is consistent with those of studies recommending that active case finding be conducted among individuals with respiratory symptoms at an increased risk of disease rather than among those in the general community. Although active case finding can detect cases of tuberculosis among individuals with respiratory symptoms, it is not cost-effective and therefore should be conducted among homeless people, illicit drug users, prison inmates, immigrants, tuberculosis contacts, people living with HIV/AIDS, and people living in deprived areas, for example. ${ }^{(9,10)}$

The prevalence of individuals with respiratory symptoms among those seeking treatment at HCFs in the present study was lower than that detected under the PNCT and that found in another study. ${ }^{(1)}$ This might be due to the fact that female patients predominated, and women are known to take better care of their health and seek medical attention more promptly when presenting with cough. The identification of cases of tuberculosis among patients presenting to HCFs with a short history of cough reinforces the importance of investigating cough regardless of its reported duration. ${ }^{(3)}$ It should be borne in mind that the prevalence of individuals with respiratory symptoms and of tuberculosis varies depending on HCF and local population characteristics, among other factors. This should be taken into consideration when planning and monitoring tuberculosis control activities in different settings.

\section{REFERENCES}

1. Ottmani SE, Scherpbier R, Chaulet P, Pio A, Van Beneden C, Raviglione M. Respiratory care in primary care services-a survey in 9 countries. Geneve: WHO; 2004.

2. Moreira CM, Zandonade E, Lacerda T, Maciel EL. Respiratory symptomatics among patients at primary health clinics in Vitória, Espírito Santo State, Brazil [Article in Portuguese]. Cad Saude Publica. 2010;26(8):1619-26. https://doi.org/10.1590/S0102$311 \times 2010000800015$

3. Bastos LG, Fonseca LS, Mello FC, Ruffino-Netto A, Golub JE, Conde MB. Prevalence of pulmonary tuberculosis among respiratory symptomatic subjects in an out-patient primary health unit. Int $\mathrm{J}$ Tuberc Lung Dis. 2007;11(2):156-60.

4. Freitas FT, Yokota RT, de Castro AP, Andrade SS, Nascimento GL, de Moura NF, et al. Prevalence of respiratory symptoms in areas of the Federal District, Brazil [Article in Portuguese]. Rev Panam Salud Publica. 2011;29(6):451-6.

5. World Health Organization (WHO). Guidelines for surveillance of drug resistance in tuberculosis. 4th ed. Geneve: WHO; 2009.

6. Instituto Brasileiro de Geografia e Estatística (IBGE). Censo Demográfico 2010: Aglomerados Subnormais--Informações

Territoriais. Rio de Janeiro: IBGE; 2010.

7. Charles N, Thomas B, Watson B, Sakthivel MR, Chandrasekeran V, Wares F. Care seeking behavior of chest symptomatics: a community based study done in South India after the implementation of the RNTCP. PLoS One. 2010;5(9). pii: e12379. https://doi.org/10.1371/ journal.pone.0012379

8. Gutiérrez C, Roque J, Romaní F, Zagaceta J. Prevalence of symptomatic respiratory cases in the Peruvian population aged 15 years and above: secondary analysis of the demographic and family health survey, 2013-2015 [Article in Spanish]. Rev Peru Med Exp Salud Publica. 2017;34(1):98-104. https://doi.org/10.17843/ rpmesp.2017.341.2771

9. Zenner D, Sourthern J, Van Hest R, Devries G, Stagg HR, Antoine D et al. Active case finding for tuberculosis among high-risk groups in low-incidence countries. Int J Tuberc Lung Dis. 2013;17(5):573-82. https://doi.org/10.5588/ijtld.12.0920

10. Golub JE, Dowdy DW. Screening for active tuberculosis: methodological challenges in implementation and evaluation. Int J Tuberc Lung Dis. 2013;17(7):856-65. https://doi.org/10.5588/ ijtld.13.0059 